\title{
Human resource management research output in Ireland between 1950 and 2010: A retrospective
}

Research Article

\author{
Ronan Carbery ${ }^{1 *}$, Patrick Gunnigle ${ }^{2}$, Michael Morley ${ }^{3}$ \\ School of Management \& Marketing, University College Cork, Ireland \\ 2 Department of Personnel \& Employment Relations, \\ Kemmy Business School, University of Limerick, Ireland \\ ${ }^{3}$ Department of Management \& Marketing, Kemmy Business School \\ University of Limerick, Ireland
}

Abstract: This paper presents a retrospective account of research output in the field of human resource management (HRM) in Ireland. We present a brief contextual overview looking at significant institutional and practice developments in the field, which, in turn were significant for curriculum, educational and research advances. We collected relevant HRM research output spanning 1950-2010, which yielded a total of 195 academic papers. Our analysis of the research output allows us to present an account of the altering profile and contribution of HRM as an academic field in Ireland and demonstrates the broadening of the field of HRM within Ireland.

Keywords: HRM research $\bullet$ retrospective • Ireland

(C) De Gruyter Open Sp. z 0.0.

\section{Introduction}

Retrospectives on an academic field, indeed on any endeavour, are fraught with danger. First, determining what precisely the field is, and what its likely boundaries are, is something of a difficult task and one which will, at minimum, engender debate. Second, having settled on some parameters concerning boundaries, what constitutes works in the field and why some might fail to be included in any analysis is always a critical concern and one that demands careful consideration and handling. Third, ascribing some importance or significance to some work, over other, even when making that ascription based on broadly agreed objective indicators, may often be a matter of perspective. Moreover, the phenomenon under the spotlight needs to be examined against the backdrop of the prevailing circumstances, for in all likelihood it is itself a product of its time. Nonetheless, even in the face of some of these complications, retrospective analyses are hugely important and may be very illuminating. Properly conducted, and situationally interpreted, they provide the possibility of demonstrating many important things about a field including its provenance and custodianship, its root developmental trajectory and eventual spread, its shifting priorities, boundaries and labels in response to prevailing contextual circumstances and, overall, its value and impact. Retrospectives can allow for a type of holography with the light being cast on the field in its entirety and rebuilt as an image that changes as the viewing platform of the observer changes creating new interpretations and understandings. Above all, a retrospective analysis offers the possibility of enhancing the systematics in a field.

In this paper, we have set ourselves the task of providing such a retrospective exposition of research output in the field of human resource management (HRM) in Ireland. In advance of explaining the methodology we used in identifying research output of relevance to our analysis and of examining the data produced by our trawl, we provide

Article note: The authors would like to thank Jack McGinley, Trinity College Dublin and Bill Roche, University College Dublin, for their advice on some of the historical aspects of this paper. 
a brief contextual overview calling attention to significant institutional and practice developments in the field, which, in turn, were consequential for curriculum, educational and research advances. We then present an account of our methodology and the sources utilised to construct the database of research output spanning 1950-2010 and yielding a total of 195 academic papers. We conclude with an account of the altering profile and contribution of HRM as an academic field in Ireland.

\section{Contextual developments in the emergence of the field in Ireland}

Whilst the field, variously referred to as 'personnel management', 'human resource management' and 'industrial relations' can trace its academic roots in the Irish education system back to the 1940s, substantial growth in education expansion in this field did not occur until the latter part of the 1960s. As McCarthy (1979) noted in his Address to the One Hundred and Thirty Third Session of the Statistical and Social Inquiry Society which that year organised a Symposium on 'Necessary Changes in Industrial Relations', universities came very late to the subject. Much of the initial teaching and research focus was squarely on industrial relations. In this early period, research activity was quite limited and was found largely in the form of reports addressing particular organisations or issues, such as the so-called 'Fogarty report' on the Electricity Supply Board (Fogarty, 1969) and the Report of the Commission of Inquiry into the infamous trade union recognition dispute between the El Company in Shannon and the Irish Transport and General Workers Union (Commission of Inquiry Report, 1968). An early exception was David O'Mahony's (1964) treatise on the Irish industrial relations system published by the then Economic Research Institute. It was, therefore, predictable that the first professorial appointments would also be in the industrial relations domain, initially Brian Hillery as ESSO Professor of Industrial Relations ${ }^{1}$ at the University College Dublin (UCD) in 1974 and later Charles McCarthy as Professor of Industrial Relations ${ }^{2}$ at the Trinity College Dublin (1979).

Though undergraduate education in the HRM field has a pedigree dating from the 1960s, this largely involved coverage as either part of business administration courses or through what might been seen as more 'pure' disciplinary fields, most notably law, industrial sociology, labour economics or industrial psychology. Professor Charles McCarthy in his 1979 address, referred to earlier, emphasised that whilst one could see the economist, the sociologist or the psychologist using phenomenon in industrial relations as material for their studies, the question was 'whether some decent academic discipline particularly related to industrial relations might be devised' (p. 61). Discrete courses only first appeared in the early 1970s, again initially in industrial relations, but later in personnel management. An important associated development was the growth in postgraduate education. Here UCD's Master of Business Studies (MBS) in Industrial Relations first offered in the early 1970s, played an important role in training a new generation of professional specialists and future academics. The first specialist academic department in the field was created at UCD in 1979.

The increased pace of industrial development from the turn of the 1960s, combined with an influx of multinational companies and led to growth in the scale and responsibilities of the specialist personnel/HRM role. This in turn required greater emphasis on the specialist education of human resource (HR) practitioners resulting in commensurate growth in the education and training provision. The establishment of a national Industrial Training Authority, AnCO (An Chomhairle Oiliuna ${ }^{3}$ ), in 1967 added momentum to professionalisation of the HR role as did growth in education and training for experience practitioners. The first courses leading to membership of the Institute of Personnel Management (now the Chartered Institute of Personnel and Development) were offered at centres in Dublin and Limerick from the early 1970s. Since then, full- and part-time undergraduate and postgraduate programmes have been established at most universities and a large number of other institutes of higher education. In 2008, courses leading to various categories of membership of the Chartered Institute of Personnel and Development (CIPD) were available at 17 centres throughout the Republic of Ireland.

In contrast to the economic growth experienced from the turn of the 1960s, the decade of the 1980s was largely characterised by economic depression and a fall in business activity. This had particularly severe consequences in industrial relations and HR terms as a result of high unemployment, in particular. Trade union density, which had grown more or less progressively from the 1930s, went into steep decline. On the other hand, these adverse trading conditions led some organisations to pursue new bases for competitive advantage, of which one potential source was the improved utilisation of a firm's employees. A particularly important academic development in the regard was

\footnotetext{
1 This current title of this post is Chair of Industrial Relations and Human Resources and the incumbent is Professor Bill Roche

2 The title of this post changed to Chair of Business Studies in 1988 with the first incumbent being the late Dr John A Murray.

3 In 1988 AnCo was replaced by FÁS (An Foras Áiseanna Saothair), as the national training and employment authority under the terms of the Labour Services Act (1987). The roles of two other state agencies, the National Manpower Service and the Youth Employment Agency, were also subsumed into
}

FÁS at this time. 
the emergence of human resource management, which was posited as a more integrated and strategic approach to workforce management than that had existed heretofore. The term has its academic and practitioner roots in the United States as far back as the early 1960s. The term 'human resource' received its first dictionary entry in 1961. Since then, it gradually emerged as the preferred nomenclature in professional circles as reflected, for example, in the renaming of the 'American Society for Personnel Administration' in 1989 which had been founded in 1948 as the 'Society for Human Resource Management' to reflect its broadened scope and influence. Today, it boasts a global membership of more than 250,000 in some 140 countries.

Academically, HRM is especially linked to the work of Michael Beer and his colleagues in Harvard University who draw extensively on industrial and organisational psychology research literature to promote the virtues of treating employees as a key organisational resource, which management must actively nurture and develop so as to maximise their potential and contribution to organisational performance (Beer et al., 1984). It also has academic roots in strategic management, most notably the work of Charles Fombrun and his colleagues who sought to explicitly link strategic management and HR practice (Fombrun et al., 1984). On the practitioner front, much of this research saw its application, at least in part, in many of the new high-technology companies that emerged in the United States from the late 1970s. A number of these companies established operations in Ireland and became the early exemplars of what became known as 'soft' HRM here, such as Wang and Digital, both of which later closed or significantly downsized though later exemplars, such as Intel and Hewlett-Packard, maintain very significant operations in Ireland. These early high-tech firms pioneered non-union operations in the country. This approach was exceptional at the time but has subsequently become common amongst many inward investing firms. Whilst the argued differences between HRM and 'traditional' personnel management are manifold, one important dimension which merits mention is that HRM represented an essentially unitartist and managerialist stance, whilst traditional personnel management was fundamentally pluralist in orientation. HRM thus became a conduit though which firms could seek to row back trade union penetration and seek to reduce union power and influence - thus providing a rationale for less emphasis on industrial relations (Guest, 1987; Tyson et al., 1994). More generally, its promotion of sophisticated recruitment and selection, investment in training and development and greater emphasis on communications with employees provided a strong rationale for a greater strategic emphasis on workforce management.

Over time, debates on the differences between personnel management, HRM and, indeed, IR have largely dissipated and 'human resource management' is now widely accepted as the umbrella term describing all aspects of workforce management in organisations including personnel management, industrial relations, organisational behaviour and HR development, and indeed research and education in these allied areas in the business school context.

\section{Methodology and data set}

In conducting our retrospective on the development trajectory of HRM research in Ireland, the methodological approach we adopted was largely quantitative and based on a rigorous search of the main abstracting services to identify peer-reviewed journal articles addressing some aspect of HRM in Ireland. It is important to state at the outset that our analysis derives from published papers in peer-reviewed journals only. We have not included authored or edited books, many of which have made a significant contribution to the literature and body of knowledge ${ }^{4}$ or unpublished papers or reports. Unquestionably, this is a limitation in our effort here because we are very conscious that such outputs have played an important role in scholarship in Ireland. Arguably, most analyses in this genre have some inherent bias by virtue of the inclusion/exclusion criteria set-down and the methods chosen to review the literature. For example, it is possible that not every computer-assisted search will be complete and not every journal article identified. Ideally, we would obtain every piece of data ever collected on the topic of concern, but some data are not published, particularly if they yield papers that do not achieve statistical significance. The major requirements for inclusion were that the paper report either quantifiable or qualitative data and that it be published in a relevant indexed journal. Some authors, such as Glass et al. (1981), advocate including unpublished studies,

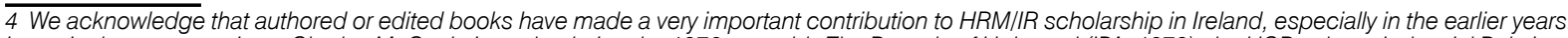
In particular we can point to Charles McCarthy's works during the 1970s, notably The Decade of Upheaval (IPA, 1973), the UCD volume Industrial Relations in Ireland: Contemporary Issues and Developments (UCD, 1987) and its successor, Irish Industrial Relations in Practice (Oak Tree Press, 1994), edited by Tom Murphy and Professor Bill Roche. 
but the present authors believed excluding them to be the best strategy in this review, arguing that the bias this exclusion may produce is recognisable - which may not be the case when including unpublished studies. Because this review is limited to published studies, however, the analyses may be assumed to be biased in that published studies tend to be those that report significant effects (Greenwald, 1975).

These limitations apply, of course, to qualitative and narrative as well as to quantitative reviews, and concerns about publication bias in favour of significant papers can be addressed with a statistical procedure addressing the file drawer problem, that is, the problem that significant papers are published whilst non-significant papers are relegated to file drawers (Rosenthal, 1979). Other biases are not so straightforward. For example, some researchers provide enough information to compute an effect size, whereas others do not. This difference may reflect a more serious bias in research sophistication. In defence of our approach, our focus on peer-reviewed papers is in line with contemporary metrics used to evaluate the academic performance of third-level institutions and particularly universities, many of which rely exclusively on Thomson Reuters ISI Web of Knowledge or the ranking system promulgated by the Association of Business Schools (ABS).

The peer-reviewed published papers included in our analysis were identified by a systematic search on a number of databases. Largely, for reasons of their coverage of the field, we made the decision in the first instance to include three significant online databases, namely, SCOPUS, Business Source Premier, and Thomson Reuters ISI Web of Knowledge. We then supplemented this search with a search of the four Irish journals in the field, namely, Economic and Social Review; Administration, Irish Journal of Management, including the contents of its forerunner; Irish Business and Administrative Research and the more recently launched Irish Business Journal. Our search of the above online databases and journals proceeded on the basis of the use of relevant keywords. The search terms used were as follows: 'HRM', 'human resource management', 'personnel management', 'industrial relations', 'training and development' and 'organisational behaviour', along with 'Ireland' and 'Irish'. As the four Irish journals were not completely indexed online, a separate hard copy content analysis using the same keywords was carried out. There were no time boundaries associated with the searches.

The searches for the three online databases revealed the following results. An analysis of the data generated on SCOPUS revealed 269 immediate papers. This comprised 20 papers for 'HRM', 158 papers for 'personnel management', 39 for 'industrial relations', 14 for 'training and development', 2 for 'organisational behaviour' and 36 for 'human resource management'. When we removed papers that overlapped on one or more search terms along with papers which had no application to an Irish context (or were concerned with Northern Ireland and the United Kingdom), there were 18 papers for 'HRM', 15 papers for 'personnel management', 23 for 'industrial relations', 6 for 'training and development', 1 for 'organisational behaviour' and 11 for 'human resource management'. It should be noted that the large reduction in SCOPUS papers for 'personnel management' post-analysis was due to the disproportionately large number of medical papers appearing in this category, which had no relevance to the study. In cases where two or more of the specific search terms were identified within one paper, the first listed of the search terms was used to categorise the papers. This process was applied for all subsequent database searches.

The second online database to be examined was ISI Web of Knowledge, and an analysis of the data generated revealed 96 relevant papers. This comprised of 7 papers for 'HRM', 9 papers for 'personel management', 37 for 'industrial relations', 17 for 'training and development', 6 for 'organisational behaviour' and 20 for 'human resource management'. The papers from ISI Web of Knowledge were cross-checked individually with the SCOPUS papers, and we removed papers that had already been indexed in SCOPUS in order to ensure no double counting occurred. We also removed papers that overlapped on one or more search terms, along with papers that had no application to an Irish context (or were concerned with Northern Ireland and the United Kingdom). There were zero papers for 'HRM', three papers for 'personnel management', six for 'industrial relations', six for 'training and development', two for 'organisational behaviour' and four for 'human resource management'.

Business Source Premier was the third database searched, and an analysis of the data generated revealed 175 papers. This comprised of 40 papers for 'HRM', 5 papers for 'personnel management', 80 for 'industrial relations', 18 for 'training and development', 2 for 'organisational behaviour' and 30 for 'human resource management'. When we removed papers that overlapped on one or more search terms or had already been indexed in SCOPUS and ISI, along with papers that had no application to an Irish context (or were concerned with Northern Ireland and the United Kingdom), there were 4 papers for 'HRM', 1 paper for 'personnel management', 3 for 'industrial relations', 4 for 'training and development', 1 for 'organisational behaviour' and 14 for 'human resource management'.

The hard copy analysis of the four Irish journals produced an additional 74 new papers that had not already been identified in the analysis of SCOPUS, Business Source Premier and Thomson Reuters ISI Web of Knowledge. 
A content analysis of every hard copy publication of these journals was carried out, and the papers were crosschecked to ensure that there was no duplication of papers already identified by the online database searches. The Irish Journal of Management (formerly Irish Business and Administrative Research) provided the majority of these papers with 42 papers, Administration produced 24 papers, Irish Business Journal (IBJ) generated 7 papers and Economic and Social Review produced 1 paper.

In total, we generated 195 papers: 72 papers for HRM/human resource management, 66 papers for industrial relations, 26 papers for personnel management, 25 papers for training and development and 6 for organisational behaviour. Within the specific parameters of the study, this is the most complete data we could gather.

\section{Results}

Table 1 presents the findings of the overall HRM research output in Ireland by decade. As anticipated, the majority of this early research centred on industrial relations and this focus pertained right up until the 1990s. From then, we find a marked increase in output of HRM-themed papers and a threefold increase in overall output. The output more than doubled again the following decade with significant increases across all allied themes that we had included in our search.

Table 1. Overall Journal Output by Decade

\begin{tabular}{|c|c|c|c|c|c|c|}
\hline \multicolumn{2}{|c|}{ Total Output by Decade } & \multicolumn{5}{|c|}{ Output by Theme By Decade } \\
\hline \multicolumn{2}{|r|}{ Papers } & \multicolumn{5}{|c|}{ Papers } \\
\hline Decade & & HRM & $\mathbb{R}$ & PM & T\&D & $\mathrm{OB}$ \\
\hline 1950 & 1 & 0 & 1 & 0 & 0 & 0 \\
\hline 1960 & 4 & 0 & 1 & 1 & 2 & 0 \\
\hline 1970 & 11 & 0 & 6 & 2 & 3 & 0 \\
\hline 1980 & 15 & 0 & 13 & 2 & 0 & 0 \\
\hline 1990 & 50 & 25 & 15 & 4 & 6 & 0 \\
\hline 2000 & 114 & 47 & 30 & 17 & 14 & 6 \\
\hline
\end{tabular}

Table 2 presents the output of HRM-related research by dominant journals over the past six decades. The primary research outlet for the small number of HRM research papers published during the first 30 years was Administration, with the majority of these papers authored by civil servants. The past 30 years have seen the field dominated by IBAR/IJM. Thus for the bulk of the period covered, Irish HRM research has largely entered the public domain via Irish journals. However, from 1990 onwards, there has been an increasing trend towards publishing in international journals such as Employee Relations, British Journal of Industrial Relations (BJIR), Personnel Review, International Journal of Human Resource Management (IJHRM), Human Resource Management Journal (HRMJ), Human Resource Management (HRM), Journal of European Industrial Training (JEIT), and Human Resource Management Review (HRMR).

Table 2. Output by Journal and Decade

\begin{tabular}{|c|c|c|c|c|c|c|c|c|c|c|c|}
\hline Decade & IBAR/ IJM & Administration & IJHRM & ESRI & $\begin{array}{l}\text { Employee } \\
\text { Relations }\end{array}$ & BJIR & IJ Man & IBJ & JEIT & $\begin{array}{c}\text { Personnel } \\
\text { Review }\end{array}$ & HRMJ \\
\hline 1950 & 0 & 1 & 0 & 0 & 0 & 0 & 0 & 0 & 0 & 0 & 0 \\
\hline 1960 & 0 & 4 & 0 & 0 & 0 & 0 & 0 & 0 & 0 & 0 & 0 \\
\hline 1970 & 2 & 8 & 0 & 0 & 0 & 0 & 0 & 0 & 0 & 0 & 0 \\
\hline 1980 & 10 & 3 & 0 & 1 & 0 & 1 & 0 & 0 & 0 & 0 & 0 \\
\hline 1990 & 17 & 4 & 4 & 4 & 3 & 2 & 2 & 0 & 3 & 3 & 0 \\
\hline 2000 & 15 & 4 & 9 & 3 & 4 & 4 & 5 & 7 & 4 & 4 & 4 \\
\hline
\end{tabular}


As the volume of research output in the social sciences has increased over recent decades, we have concurrently seen greater debate on research quality, impact and relevance. Much effort has been put into the development of journal rankings within fields, and more laterally, there have been searching attempts at examining the nature of the research agendas pursued and the actual impact of research. Against this backdrop, Adler and Harzing (2009) have made a call for more valid ways to assess scholarly contributions that truly promote the advancement of relevant 21 st-century knowledge. There is little doubt the barometers of quality in research outputs and the nature of research impact will significantly grow as a focus in the time ahead as the relevance of scholarship remains under scrutiny and as new emerging areas demand attention. Leaving aside the much bigger debate on rigor, relevance and impact, for the purposes of our rudimentary enquiry in this piece, we simply examined the number of papers that fell within our search criteria that appeared in ISI listed periodicals as one barometer of quality invoked. On this front, as Table 3 highlights, approximately one quarter of the output $(24.5 \%)$ was published in a journal included for coverage by the ISI. In addition, we can observe that the proportion of papers published in journals covered by the ISI has been increasing over time. Of the 50 papers published in the 1990 s, $26 \%$ was ISI ranked, whilst in the 2000 s, the equivalent figure was $30.7 \%$. Using the ABS ranking as an alternative barometer, our results show that $65.1 \%$ of overall output appeared in journals included in the ABS ranking. This has been consistently high since the 1980 s, with $65.8 \%$ of papers published in 2000 s appearing in journals included in the ABS rankings.

Table 3. Comparison of Overall Output vs. Output in Journals Covered by the ISI and ABS

\begin{tabular}{cccc}
\hline & \multicolumn{2}{c}{ Output } & \\
Decade & Overall Publications & ISI ranked & ABS ranked \\
\hline \hline 1950 & 1 & 0 & 0 \\
1960 & 4 & 0 & 0 \\
1970 & 11 & 0 & 2 \\
1980 & 15 & 0 & 11 \\
1990 & 50 & 13 & 39 \\
2000 & 114 & 35 & 75 \\
\hline
\end{tabular}

Table 4 provides a more detailed profile of the ABS rankings by decade. The top ABS journal ranking is $4^{*}$ and the lowest is $1^{*}$. This data indicates that the majority of ABS rankings secured by Irish HRM papers have been achieved in $1^{*}$ ranked journals. This may partially be explained by the fact that Irish journals (such as IBAR/IJM, which represent an important outlet for Irish research and which account for a significant portion of the output) achieve a $1^{*}$ rating in the ABS ranking, given their status as 'national' journals. Conversely, of the total 114 papers published in the 2000 s, just $5.2 \%$ were in top $4{ }^{*} \mathrm{ABS}$ ranked journal. This compares to $6 \%$ in the $1990 \mathrm{~s}$.

Table 4. Number of Publications in ABS Ranked Journals by Decade

\begin{tabular}{ccccc}
\hline & ABS rankings by decade & & $\mathbf{1}^{*}$ \\
\hline \hline $\mathbf{4}^{*}$ & $\mathbf{3}^{*}$ & 0 & 2 \\
1970 & 0 & 0 & 0 & 10 \\
1980 & 1 & 0 & 10 & 20 \\
2000 & 3 & 6 & 24 & 23 \\
\hline
\end{tabular}

Table 5 looks at which institution the 48 ISI ranked publications emerged from. An institute was accredited with an affiliation on ranked publications regardless of the order of author listing. Where two or more authors from the same institute were credited as co-authors, the institute was only credited once. University of Limerick (UL) contributed to 14 (29.2\% of overall output in ISI listed journals) of the 48 ISI ranked papers. Various British institutes were affiliated with 10 papers, and Queens University Belfast were affiliated with 7 papers $(14.6 \%$ of overall papers published in ISI listed journals). UCD was the second highest Irish institute with 6 (12.5\% of published output in ISI covered journals) papers, Dublin City University contributed to 4 (8.3\% of overall output covered in the ISI) papers, and NUIG to 3 (6.3\% of overall ISI papers). 
Table 5. ISI Ranked Output by Institution

\begin{tabular}{lcc}
\hline & Institutional Rankings & \\
\hline \hline & UL & Number of papers in ISI listed journals \\
UK Institutes & 14 \\
Queens & 10 \\
Other Euro & 7 \\
UCD & 7 \\
Other Global & 6 \\
DCU & 5 \\
NUIG & 4 \\
Commercial & 3 \\
Other US & 3 \\
Ulster & 3 \\
Other Irish & 2 \\
TCD & 2 \\
Dundalk & 1 \\
DIT & 1 \\
\hline
\end{tabular}

Tables 6 and 7 present the overall HRM-related output by institute by decade. First, Table 6 looks at output where all authors on papers are given equal weighting. Again, where two or more authors from the same institute were credited as co-authors, the institute was only credited once. Civil services bodies contributed to the majority of research from 1950 through the 1970s (with much of this being published in Administration). UCD was the dominant institute in the 1980s; however, since 1990, UL has contributed to a significant proportion of HRM-related research output. The past decade has also seen significant increases in the HRM-related research output of Trinity College Dublin, NUIG, Queens University, UCC, UCD and DCU.

Table 7 presents the same overall HRM-related output by institute by decade; however, in this instance, only the affiliations of first-named authors were counted. The findings are broadly similar, with UCD dominant in the 1980s and UL coming to the fore in the subsequent two decades.

\section{Conclusions}

Pedagogy and research in HRM in Ireland has been on a strong developmental trajectory since the 1970s when the first Chairs were created at UCD and TCD. Whilst we were relative latecomers in the institutionalisation of the field in academic quarters, and, to a certain extent in practice, reflecting our relatively late industrialisation and our path to the securing of inward foreign direct investment, much has been achieved. The pedagogical trajectory is evidenced by, inter alia, the recruitment of a cohort of specialist teaching faculty, the incorporation of the field into undergraduate and graduate curricula culminating in the emergence of specialist bachelor and master degrees and of a professional managerial cohort. In addition to being exposed to a specialist education, these managers were, and continue, to be served by a parallel professional body: the CIPD, a body which itself has played an important role in both the promotion of human resource management related education and professional practice and which now represents almost 6,000 members in Ireland. There is little doubt that these developments, in combination, represent a significant architecture for the field. They have been bolstered by the emergence of an academic body of research knowledge that has been incorporated into the curricula being taught in specialist undergraduate, graduate and executive programmes. Thus, in seeking to answer Professor McCarthy's 1979 question on whether some decent field might emerge, we can reply with some confidence that we have at least travelled some distance.

Our analysis of a significant portion of research work, namely, published papers in refereed journals covered by three major online databases (Thomson Reuters ISI, SCOPUS and Business Source Premier), supplemented by a content analysis of all the published issues of the four relevant Irish Journals, unearths several trends and developments in a body of work comprising 195 papers. Early research output in the field in Ireland largely focused 


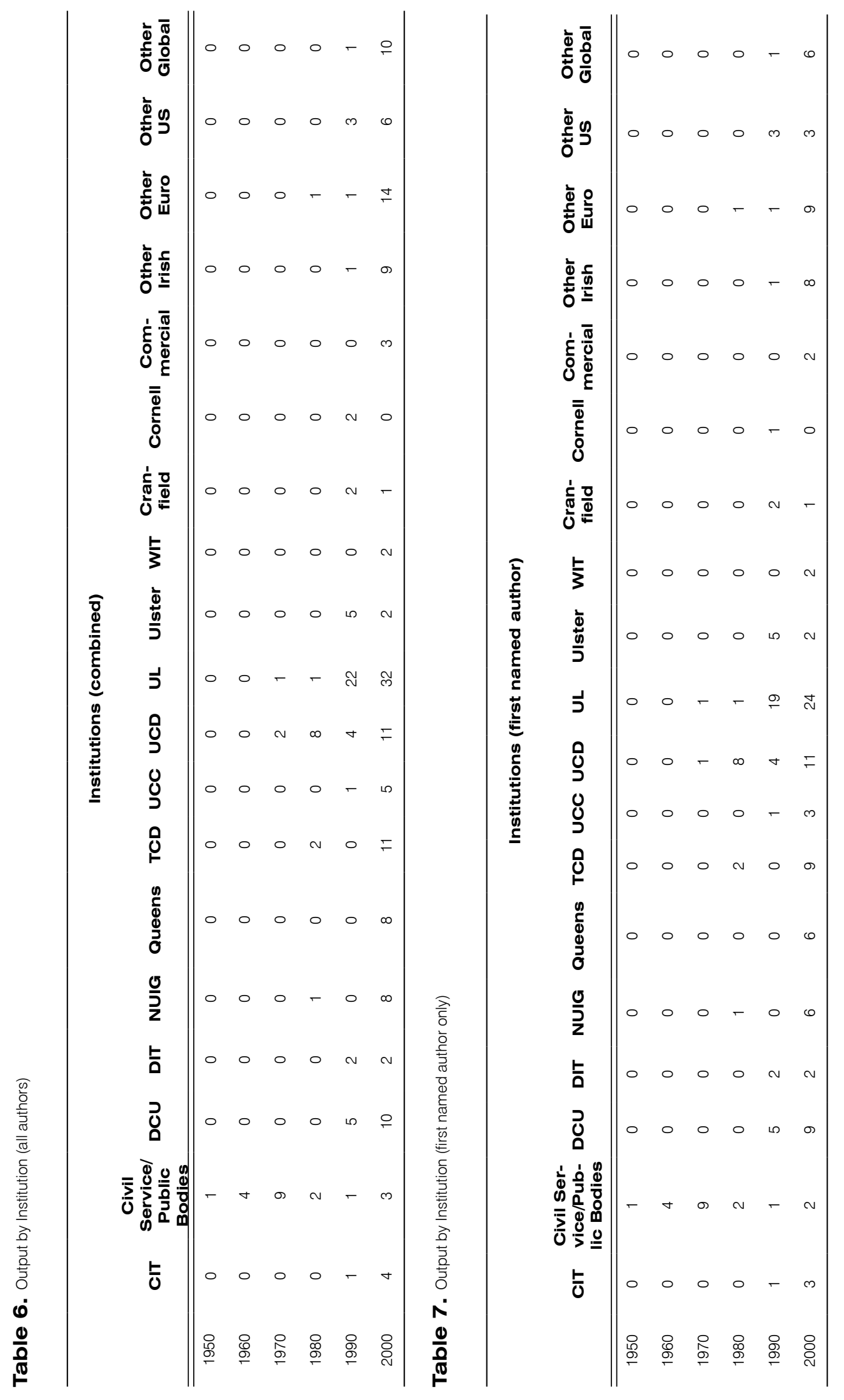


on industrial relations matters, but over time mirroring transitions occurring elsewhere, this gave way to a broadening of research output to reflect the eventual emergence and growing influence of HRM as the preferred nomenclature. With respect to the outlet for the research and writing, early work in the 1950s and 1960s through to the 1980s appeared in the established Irish journals, Administration and Irish Business and Administrative Research, both of which represented, and continue to represent, important indigenous outlets. Whilst the period since the $1990 \mathrm{~s}$ has continued to see the sustaining of those and other national journals, the evidence also points to a significant increase in the appearance of Irish research outputs in international journals. This is hardly surprising since this period has seen a burgeoning number of journals acting as specialist outlets, a significant growth in postgraduate education and candidates registered for research degrees, a growth in funding opportunities and a premium placed on securing funding and engaging in international collaborations as part of the development of a balanced portfolio of activity in an academic career.

Tackling the many complex issues surrounding the question of the impact and relevance of this research is beyond the scope of our analysis here, but we did isolate the numbers appearing in ISI and ABS ranked journals, both of which are invoked, though this is often contested, as barometers of the quality of the output. Here again the past two decades appear to represent the strongest trajectory with this period resulting in an increase in output in journals covered by these rankings. Taken in its entirety, it is plausible to suggest that this body of work has made an important theoretical contribution towards explicating the nature of HRM in Ireland, its foundations, its predominant concerns at particular points in time and its contribution at individual, organisational and societal level. Importantly, in this context, if we view HRM as a socially derived, institutionally embedded phenomena characterised by internal as well as external influences, there are few substitutes for such a well-developed, contextually informed body of knowledge.

\section{References}

Adler, N. and Harzing, A.W. (2009) When Knowledge Wins: Transcending the Sense and Nonsense of Academic Rankings, The Academy of Management Learning \& Education, 8(1), pp. 72-95.

Beer, M., Spector, B., Lawrence, P.R., Quinn-Mills, D. and Walton, R.E. (1984) Managing Human Assets: The Groundbreaking Harvard Business School Program, New York: Macmillan.

Commission of Inquiry Report (1969), 1968 Dispute Between ITGWU and El Company Ltd, Dublin: Stationery Office.

Fogarty, M.P. (1969) Final report of the Committee on Industrial Relations in the Electricity Supply Board, Dublin: Stationery Office..

Fombrun, C., Tichy, N. and Devanna, M. (1984) Strategic Human Resource Management, New York: Wiley.

Glass G.V., McGaw B. and Smith M.L. (1981) MetaAnalysis in Social Research, Beverly Hills, CA: Sage.
Greenwald, A.G. (1975) Consequences of Prejudice Against the Null Hypothesis, Psychological Bulletin, 82, pp. 1-20.

Guest, D. (1987) Human Resource Management and Industrial Relations, Journal of Management Studies, 24(5), pp. 503-521.

McCarthy, C. (1979) 'Industrial Relations: The Contribution of the Universities', in Proceedings of the Second Meeting of the One Hundred and ThirtyThird Session of the Statistical \& Social Inquiry Society of Ireland, Dublin: Academy House.

O'Mahony, D. (1964) Industrial Relations in Ireland: The Background, Dublin: Paper no. 19, Economic Research Institute.

Rosenthal R. (1979) The 'File Drawer Problem' and Tolerance for Null Results, Psychological Bulletin, 86, pp. 638-641.

Tyson, S., Witcher, M. and Doherty, N. (1994) Different Routes to Excellence, Cranfield School of Management: Cranfield University. 